\title{
Arquitectura sagrada en Burundi
}

\author{
Sacred Architecture in Burundi \\ Luigi Leoni y Chiara Rovati · Fondazione Frate Sole (Pavia, Italia)
}

https://doi.org/10.17979/aarc.2013.3.0.5081

\section{RESUMEN}

Una iglesia debe tener el rostro y el corazón de la tierra y del pueblo en el que se destaca. Para proyectar los espacios para el culto, es importante sumergirnos en la vida de las personas, compartir sus visiones y verdaderas aspiraciones y conocer el lenguaje de sus corazones a través de la observación de la naturaleza. La experiencia en África nos ha sugerido la expoliación de cualquier perjuicio para dar la bienvenida a la novedad de un mundo virgen, capaz de inspirar, en su simplicidad, la formas más esenciales y verdaderas, sin artificios y reminiscencias de otros mundos.

\section{ABSTRACT}

A church must have the face and the heart of the land and of the people where it is built. To project the spaces for worship, it is important to know the lives of people, to share their visions and true aspirations and to learn the language of their hearts, also through the observation of nature. The experience in Africa has suggested the removal of any preconception to welcome the novelty of a virgin world, capable of inspiring in its simplicity, the most essential forms and true, without artifice and reminiscences of other worlds.

\section{PALABRAS CLAVE}

Arquitectura africana; espacio sagrado; proyecto; evangelización; misión.

\section{KEYWORDS}

African architecture; sacred space; design; evangelization; mission. 
La Iglesia es misionera. Ella anuncia a Cristo Señor a través de la predicación y el testimonio de la fe. El impulso de la evangelización siempre ha ido acompañado de un gran fervor en la construcción de lugares de culto que expresan la belleza del mensaje de salvación. Pero la pregunta es: ¿en qué fuente hay que inspirarse? Todavía nos apoyamos en nuestras certezas del pasado o, más bien, tenemos la valentía de abrirnos a nuevos horizontes?

A principios del siglo $\mathrm{XX}$, el descubrimiento del arte africano abrió el camino para el estudio y la investigación de eventos artísticos hasta entonces desconocidos, capaces de dar un nuevo impulso a la creatividad. Se abandonaron vías ya recorridas para explorar nuevos caminos.

Como había ocurrido en el inicio de la era cristiana, cuando el arte recibió nueva vida gracias al mensaje del Evangelio produciendo nuevas formas de expresión artística, hoy en nuestro mundo globalizado estamos llamados a dar la bienvenida a las diferentes fuentes de inspiración de todos los continentes, para crear formas sin precedentes con un proceso de encarnación en cada tipo de realidad.

Muy a menudo, en los siglos pasados, la solución que se adoptó en los países de misión fue la de exportar modelos preconfeccionados de iglesias, destinados a los países europeos, sin prestar atención a la sensibilidad y a la cultura de los pueblos, a favor de los cuales se tenían que construir espacios para reuniones religiosas. Esto se debió probablemente al hecho de que se creía que era útil exportar todo lo que se producía en nuestros países avanzados, como un logro tecnológico y artístico. Además, en el pasado no se estaba todavía preparado para apreciar los valores de la expresión artística de los pueblos africanos, del América del Sur o del Extremo Oriente.

Se debe tener en cuenta que cada arquitectura $-\mathrm{y}$ en particular una iglesia- debe tener el rostro y el corazón de la tierra y del pueblo en el que se realiza. Es esencial conocer la realidad de un territorio, las costumbres y tradiciones del pueblo, sus casas, sus lugares y herramientas de trabajo, sus materiales de construcción, así como su historia y sus características ambientales para acercarse a la mentalidad de los que habitan esa tierra.

Así como Cristo se encarnó en nuestra realidad terrena, el artista está llamado a encarnarse en la reali-

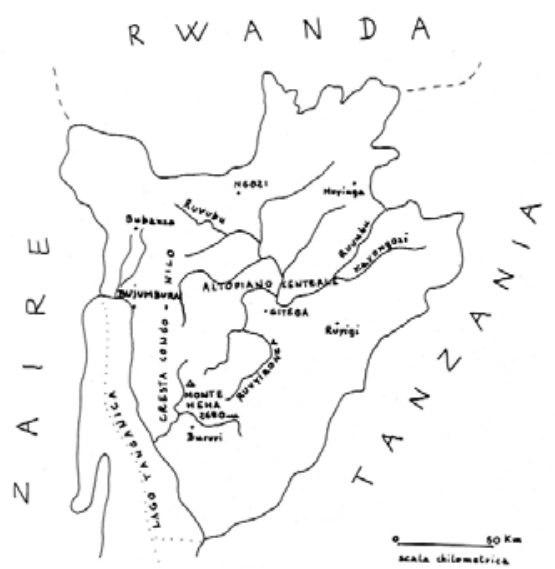

Fig. 01. El territorio de Burundi.

dad en la que debe operar. Esta es la aventura que vivió Gauguin en los países tropicales, entre otros pintores modernos. Ellos se inspiraron en el arte y en la vida de esas personas, fascinados por la cultura que los caracterizaba. Para muchos artistas de principios del siglo XX, el arte africano fue una fuente de inspiración para volver a los orígenes de la creatividad.

Lo que se consiguió en el plano pictórico, tendrá que producirse también a nivel arquitectónico, madurando la necesidad de estudiar e investigar los modelos nativos de cada país.

En los años 80 del siglo pasado, junto con el padre Costantino Ruggeri —un fraile menor franciscano y artista de gran prestigio en Italia-, me llamaron a estudiar y realizar algunas iglesias en Burundi, en concreto en la misión franciscana de Kayongozi, perteneciente a la diócesis de Ruyigi. Para proyectar esos espacios para el culto, nos pareció importante sumergirnos en la vida de las personas, compartir sus visiones y verdaderas aspiraciones y conocer el lenguaje de sus corazones, a través de la observación de la naturaleza que los rodeaba: el esplendor de la luz del sol, el color de la tierra, el flujo sinuoso de los ríos, los movimientos de los cerros...

La experiencia en África nos ha sugerido olvidar cualquier perjuicio para dar la bienvenida a la novedad de un mundo virgen, capaz de inspirar, en su simplici- 

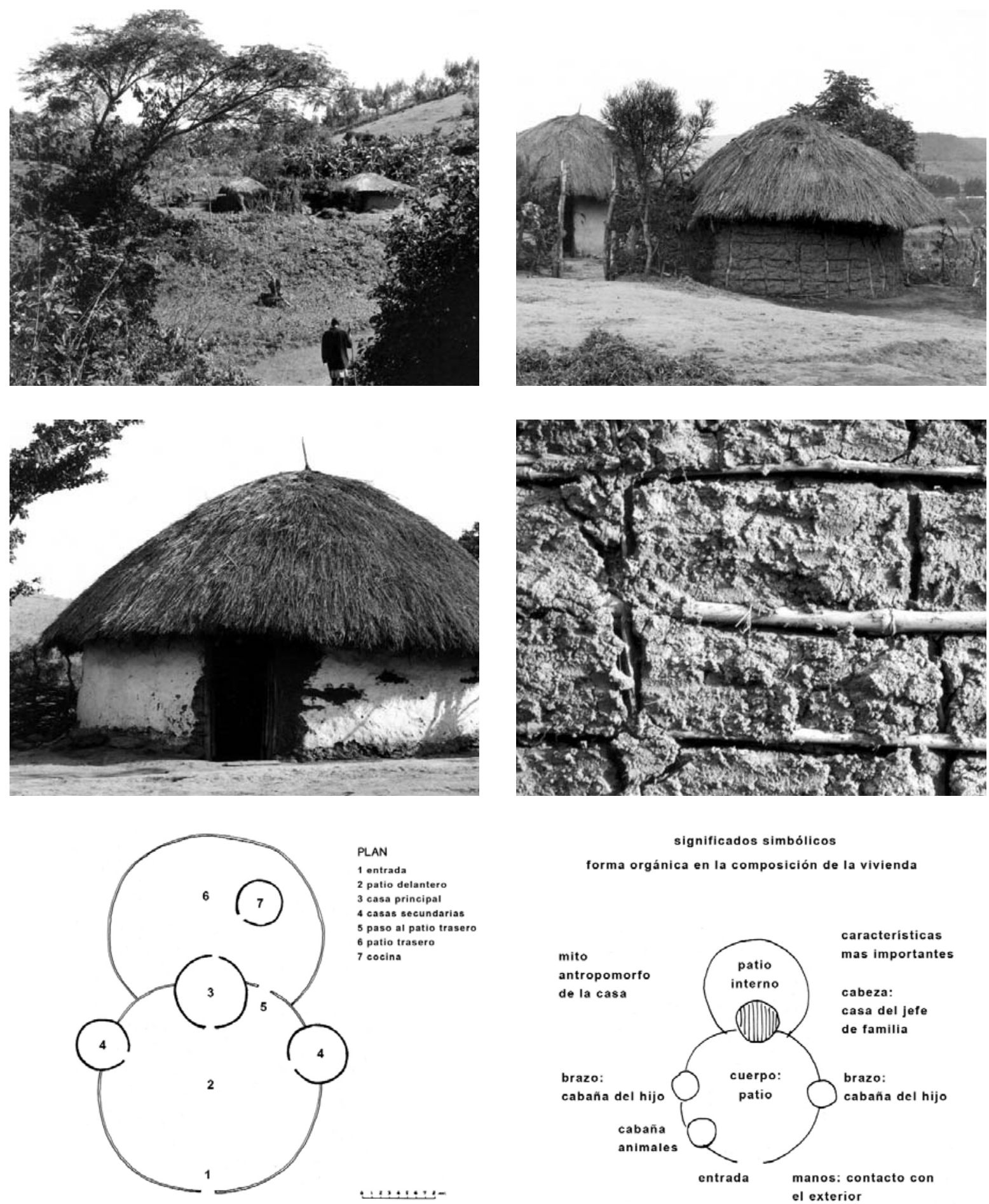

significados simbólicos

forma orgánica en la composición de la vivienda

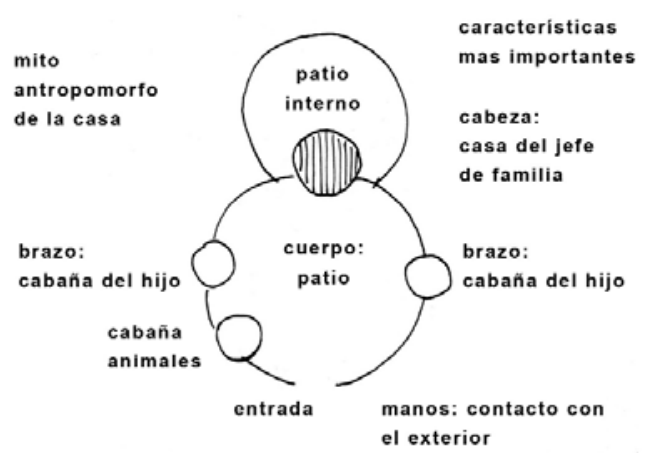


dad, las formas más esenciales y verdaderas, sin artificios y reminiscencias de otros mundos y de otras tradiciones que están muy lejos de la vida que se desarrolla en una cabaña de barro y cubierta de paja.

Burundi está en el corazón de África central, y su territorio, a excepción de la banda que linda con el lago Tanganika, tiene cerros y montañas (Fig. 01). El paisaje se caracteriza por una extrema dispersión de las viviendas (Fig. 02). Tradicionalmente, no existen agregaciones que determinen la conformación de pueblos. Faltan centros de atracción que pongan en relación las unidades individuales. Además de la capital, Bujumbura, que asumió la apariencia de ciudad, tal como la entendemos nosotros, gracias a los modelos extranjeros, y Gitega, la primera capital hasta la época colonial que actualmente se ve como un pueblo, la población restante, que se dedica a la agricultura y a la cría del ganado, vive en rugos, grupos de cabañas, generalmente rodeados por una muralla, situados en las laderas de los cerros (Fig. 03). Fuera de los recintos hay terrenos de tierra cultivada. Cuando el clima lo permite, en altitudes que varían entre 1.000 y 1.800 metros, las viviendas están en las plantaciones bananeras.

El alojamiento tradicional de las viviendas de Burundi y Ruanda se debe a factores históricos que han fortalecido la tendencia de los grupos étnicos presentes a cerrarse en su propio entorno, estructurado como una unidad separada y autosuficientes sin ninguna relación unos con otros. Hasta la edad moderna, ni siquiera se ha comprobado la necesidad de establecer puntos de encuentro fuera de las viviendas. El sistema de vida, básicamente vinculado a la subsistencia diaria, no favoreció la constitución de asociaciones, tales como escuelas, hospitales, lugares de reunión.

En los territorios del Tercer Mundo ocurre el fenómeno de los cambios forzados y los procesos de transformación, que producen una ruptura con los modos de vida tradicionales. La ruptura del equilibrio existente fue causado por el colonialismo y el imperialismo. Tenemos que fomentar la búsqueda de lo auténtico, lo genuino y lo culturalmente específico, sin pretender reconstruir las antiguas culturas en su originalidad, pero

Fig. 02. Casas y rugo, Burundi, 1979.

Fig. 03. Casas en Burundi, 1979.

Fig. 04. Cabaña, Murundi (Burundi), 1979

Fig. 05. Cabaña en construcción, Murundi (Burundi), 1982; detalle del muro exterior (poto poto).

Fig. 06. Esquema de una casa tradicional en Burundi.

Fig. 07. Significados simbólicos de una casa tradicional en Burundi. usándolas para un estudio adecuado de los espacios asociativos necesarios en la sociedad moderna.

En Burundi, es fundamental el conocimiento y la afirmación de los valores expresados en la casa tradicional, el núcleo de agregación principal, para respetar el carácter peculiar del ambiente, y sobre todo para capturar las riquezas, a fin de mostrar el camino para diseñar nuevos espacios.

Para el proyecto de las iglesias, nuestra principal fuente de inspiración fue la vivienda de los Barundi y la forma en que se unen a nivel familiar y de clan. Es típico el rugo, una valla que bordea el espacio privado de una familia o de un grupo de familias con lazos de parentesco.

La valla se forma normalmente con ramas y follaje hasta una altura de dos metros. La forma perimetral es libre, preferentemente circular. Hasta los años 80, la casa era esencialmente una cabaña con forma circular con estructura de madera en las paredes y en el techo. El revestimiento de las paredes estaba hecho de barro (poto poto) (Fig. 04-05) y se combinaba armoniosamente con el terreno de los alrededores, fundiéndose con él gracias al material y al color usados. La cubierta estaba hecha de varias capas de paja que se debíann renovar con frecuencia.

La casa murundi tiene en sí significados simbólicos extraordinarios. Su composición está relacionada con formas antropomórficas orgánicas primordiales. El rugo o patio central es como un gran vientre. En la posición de la cabeza se coloca el inzu, la residencia del jefe de la vivienda. Los brazos del rugo se abren para proteger las casas de los hijos, hasta la entrada que muestra el contacto con el exterior (Fig. 06-07).

Este sistema ha sido adoptado para el amplio patio que sirve como atrio de la iglesia diseñada por mí y por el Padre Constantino, dedicada a San Francisco de Kayongozi (Fig. 08). En él está la imagen y el significado de la vivienda-rugo: el lugar de las relaciones íntimas a nivel familiar se expande en las relaciones de la comunidad que se reconocen unidos bajo el signo de Cristo. El marco arbolado abarca el espacio bajo el cielo de la misma manera emblemática de la columnata de San Pedro del Vaticano.

Así, la nueva iglesia fue pensada específicamente dentro de un rugo para crear un atrio siguiendo el espíritu de la población local. La pared exterior fue construida con ladrillos y revestida de yeso de las mismas 

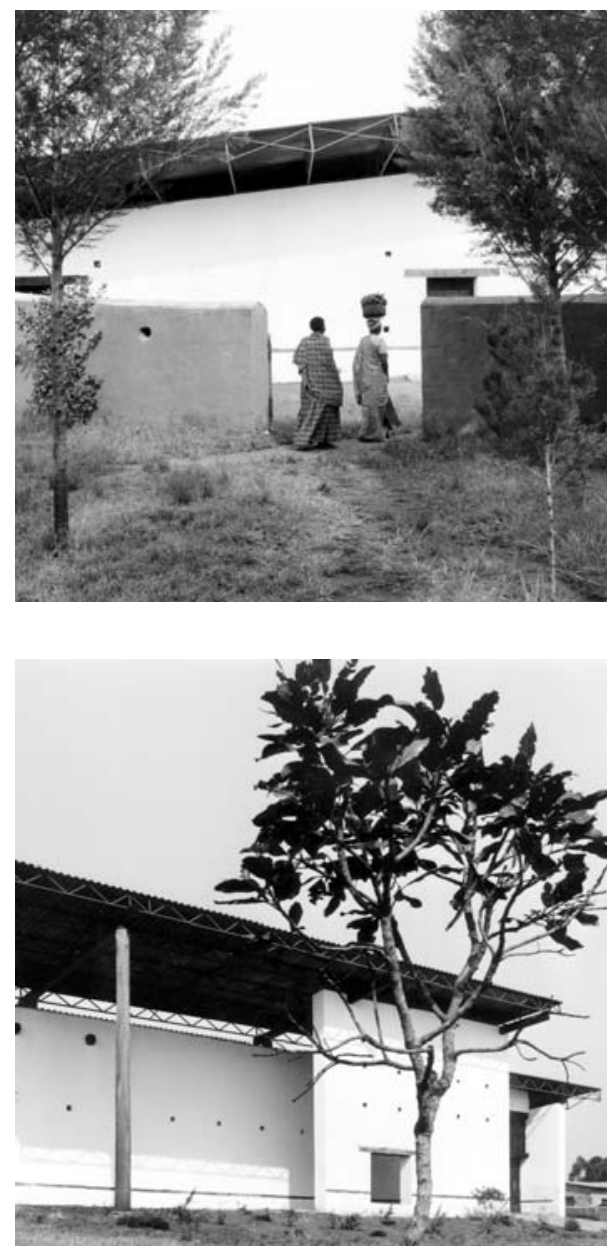

Fig. 08. Padre Costantino Ruggeri, San Francisco, Kayongozi (Burundi), 1983; acceso.

Fig. 09. Visión general.

Fig. 10. Fachada.

Fig. 11. Detalle del presbiterio.
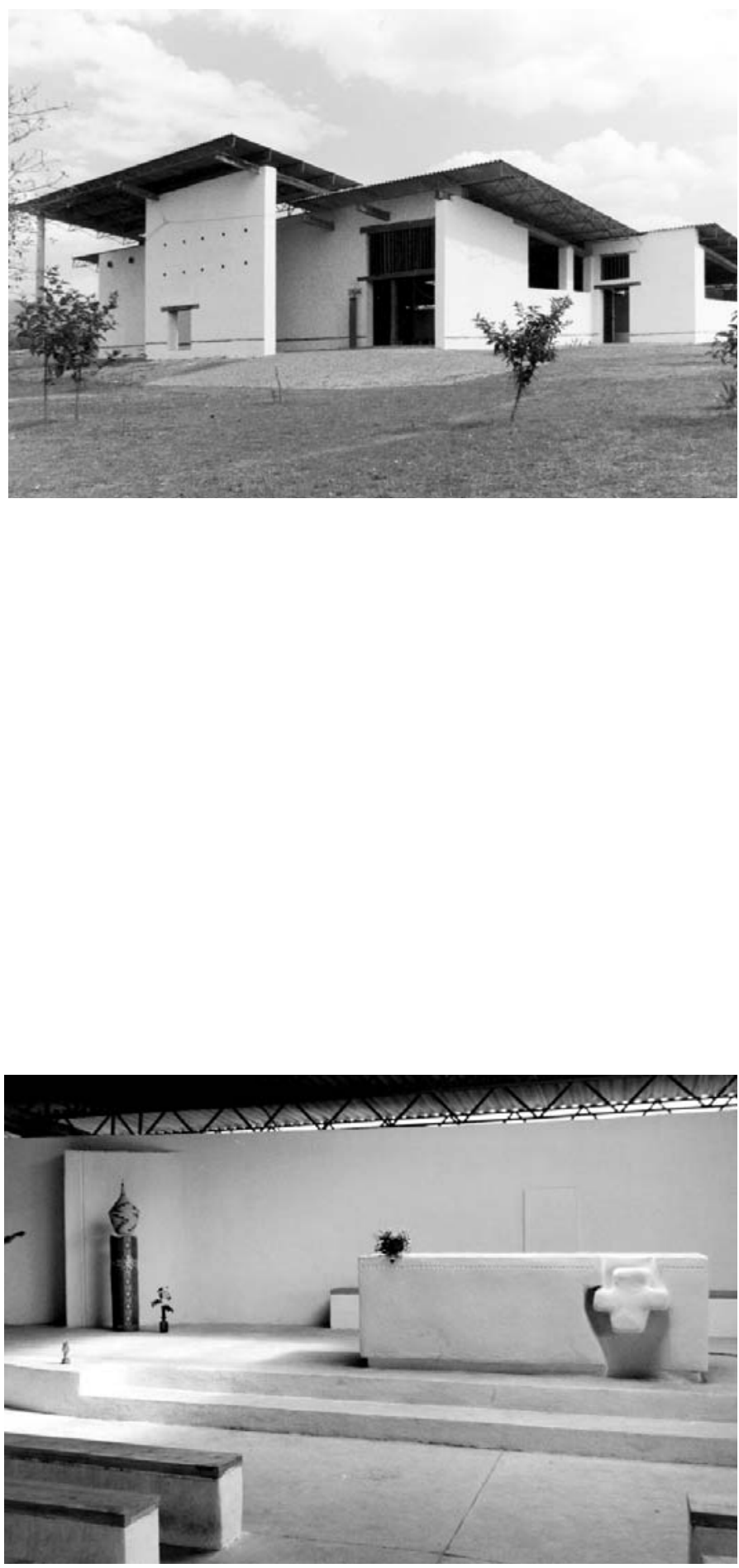

Actas del Congreso Internacional de Arquitectura Religiosa Contemporánea 3 (2013) 


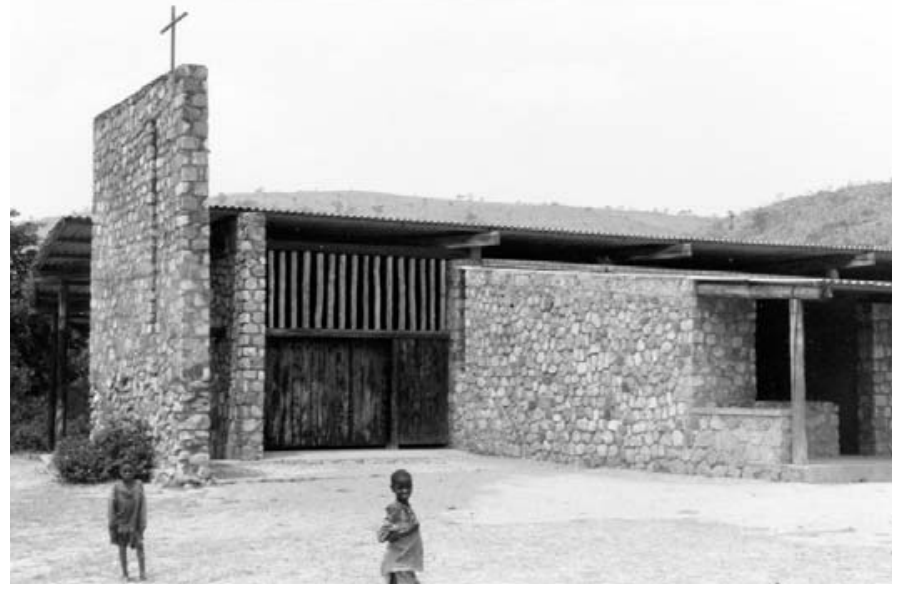

Fig. 12. Luigi Leoni, San Bernardino, Nyakayi (Burundi), 1987; fachada. características plásticas y de color que sus viviendas (Fig. 09-10). La estructura se realizó con columnas de eucalipto procedentes de los bosques próximos a la misión. Todo se hizo en la esencialidad y en la pobreza. Los mismos objetos sagrados realizados por nosotros se inspiran en las formas de las canastas e instrumentos domésticos barundi.

El espacio de la iglesia no es ciertamente inédito. El primer anuncio del Evangelio en estas tierras se produjo sólo en la segunda mitad del siglo pasado. Por lo tanto, se trataba de inventar formas que reprodujeran en la sencillez, en la pureza y en la pobreza los valores expresados por la arquitectura residencial, colocada naturalmente y armoniosamente en el paisaje. Por esta razón, la apariencia externa de los revestimientos de las paredes se funde, gracias a la materia y al color, con el suelo de los alrededores. Los bancos internos son tablas de madera cortadas con sierras de mano, el altar se moldea suavemente en formas plásticas y la custodia eucarística reproduce la canasta reconocida como un contenedor de objetos preciosos para la vivienda (Fig. 11).

En el atrio hay signos de fuego y de agua, los elementos primordiales, los signos de la vida de cada hombre. En las viviendas barundi, el fuego se enciende en el interior del inzu para calentar las noches frías, y en una cabaña especial para cocinar. El agua es el elemento más preciado. En las marais del valle es pútrida, portadora de enfermedades. En la fuente bautismal, por el contrario, es signo de regeneración, de nacimiento a una nueva vida.
La iglesia de San Bernardino, en Nyakay, fue realizada con bloques de piedra traídos por la población local en el ubumue (día del trabajo en común). Las piedras están unidas con barro. Para garantizar la seguridad del edificio en la parte superior del muro se ha construido un zuncho de hormigón armado (Fig. 12-13).

La iglesia de Santa Clara, en Nyamugari, es la más simple, por su planta general y su composición. Y también la más pobre. En su desnudez toma fuerza solo y exclusivamente gracias a los pocos signos esenciales que tiene (Fig. 14). Aquí se puede escuchar el canto del corazón, que con toda libertad puede subir al cielo sin pretensión o superestructuras, en la pureza original de las cosas, en la sencillez de los gestos que se hacen palabra viva.

El mismo mensaje fuerte que sentí un par de años después cuando visité, en la sabana, una cabaña donde una pequeña comunidad de cristianos se reunía para vivir la celebración eucarística (Fig. 15). Todo aquí era superfluo, frente a la poderosa señal de la pequeña cruz que se encuentra en la pared del fondo. Descubrí esta capilla en Tanzania, en un lugar no muy lejos de la frontera con Burundi, cuando después del año 2000, fui llamado por los hermanos franciscanos a vivir otra experiencia de diseño de iglesias cerca del lago Victoria. Me quedo grabado en el corazón la emoción que sentí, y la guardo como una gracia recibida.

En ese lugar sagrado, con piso de tierra, paredes de juncos y techo de paja, sentí brillar la presencia del Espíritu de Dios que se manifiesta en la riqueza de la pobreza: el esplendor radiante del misterio de la salvación. 


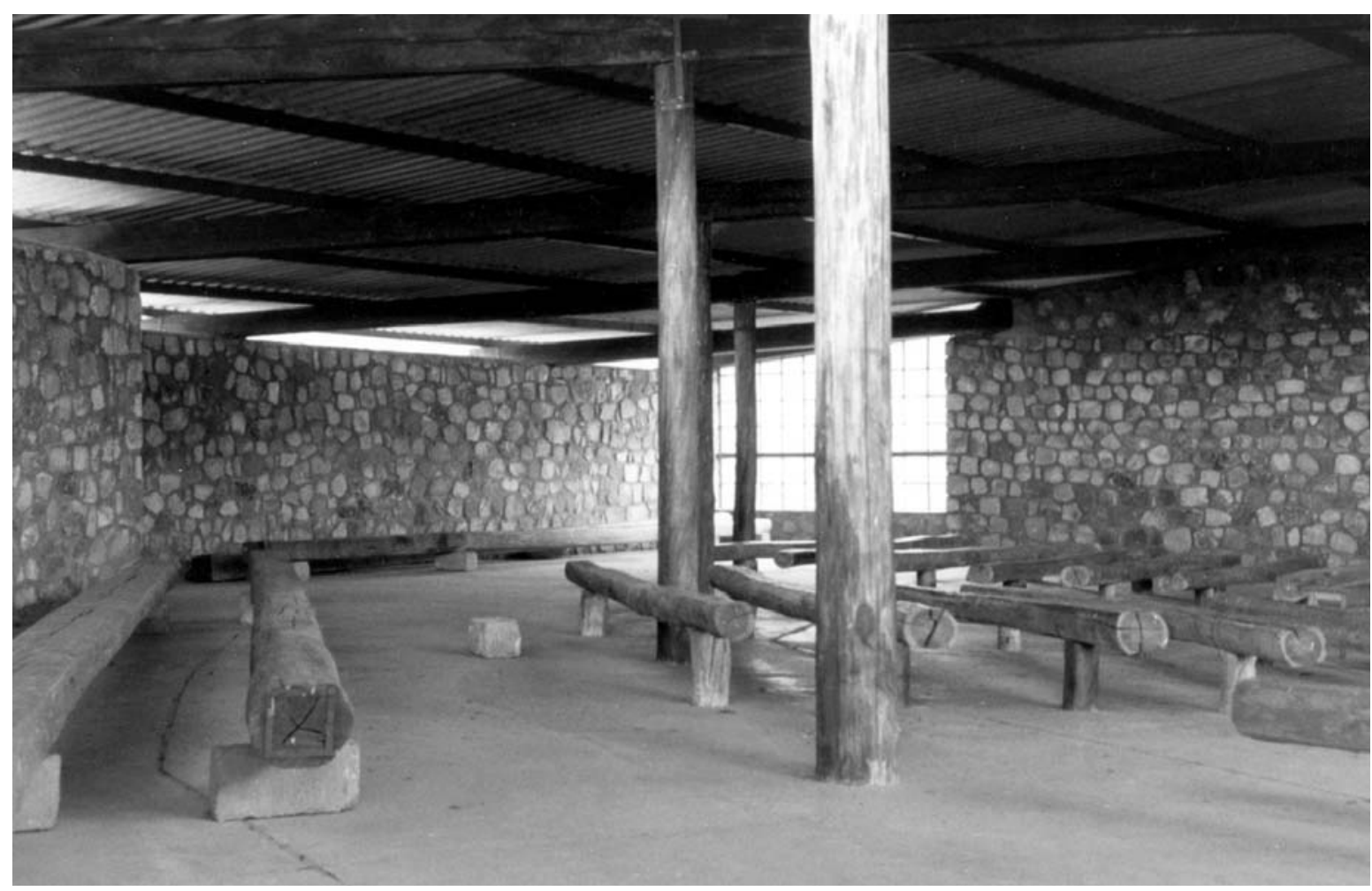

Fig. 13. Luigi Leoni, San Bernardino, Nyakayi (Burundi), 1987; interior.

Fig. 14. Padre Costantino Ruggeri, Santa Clara, Nyamugari (Burundi), 1979.

Fig. 15. Capilla en la sabana (Tanzania), 2002 (en la página siguiente).

\section{BIBLIOGRAFÍA}

AA.VV., Le rugo dans la tradition burundaise (Bujumbura: Le Palais des Arts et de la Culture du Burundi, 1977).

Francoise Cazenave Piarrot et al., Geographie du Burundi. Le pays, les hommes (París: Edicef, 1979).

Guglielmo Guariglia, I Burundi: una società sapienziale (Milán: Opera Universitaria dell’Università Cattolica, 1980).

Leonidas Ndoricimpa \& Claude Guillet, L’arbre-mémoire. Traditions orales du Burundi (París: Karthala, 1984).

René Collart \& Georges Celis, Burundi: trente ans d'histoire en photos: 1900-1930 (Namur-Bujumbura: Tournais, 1988).

Xavier Richer, Burundi Touristique (Mowbray: Delroisse, 1977).

\section{CRÉDITOS DE LAS ILUSTRACIONES}

Todas las ilustraciones pertenecen al archivo de los autores.

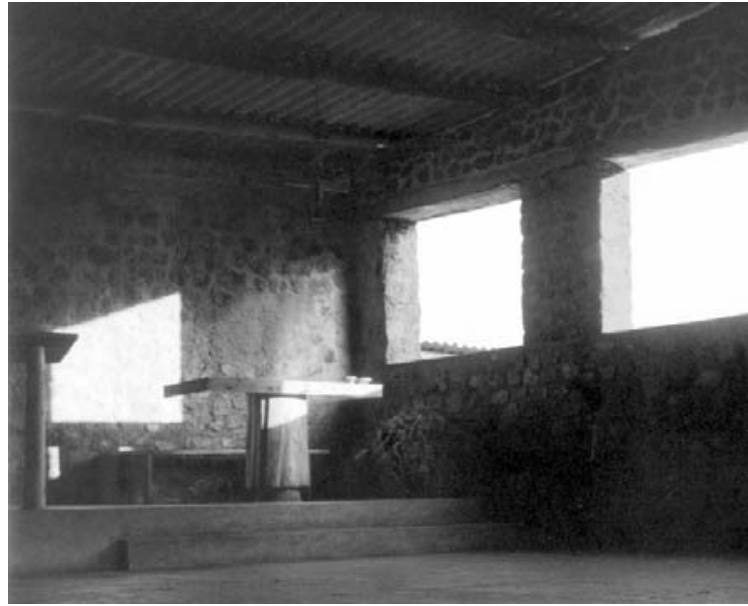




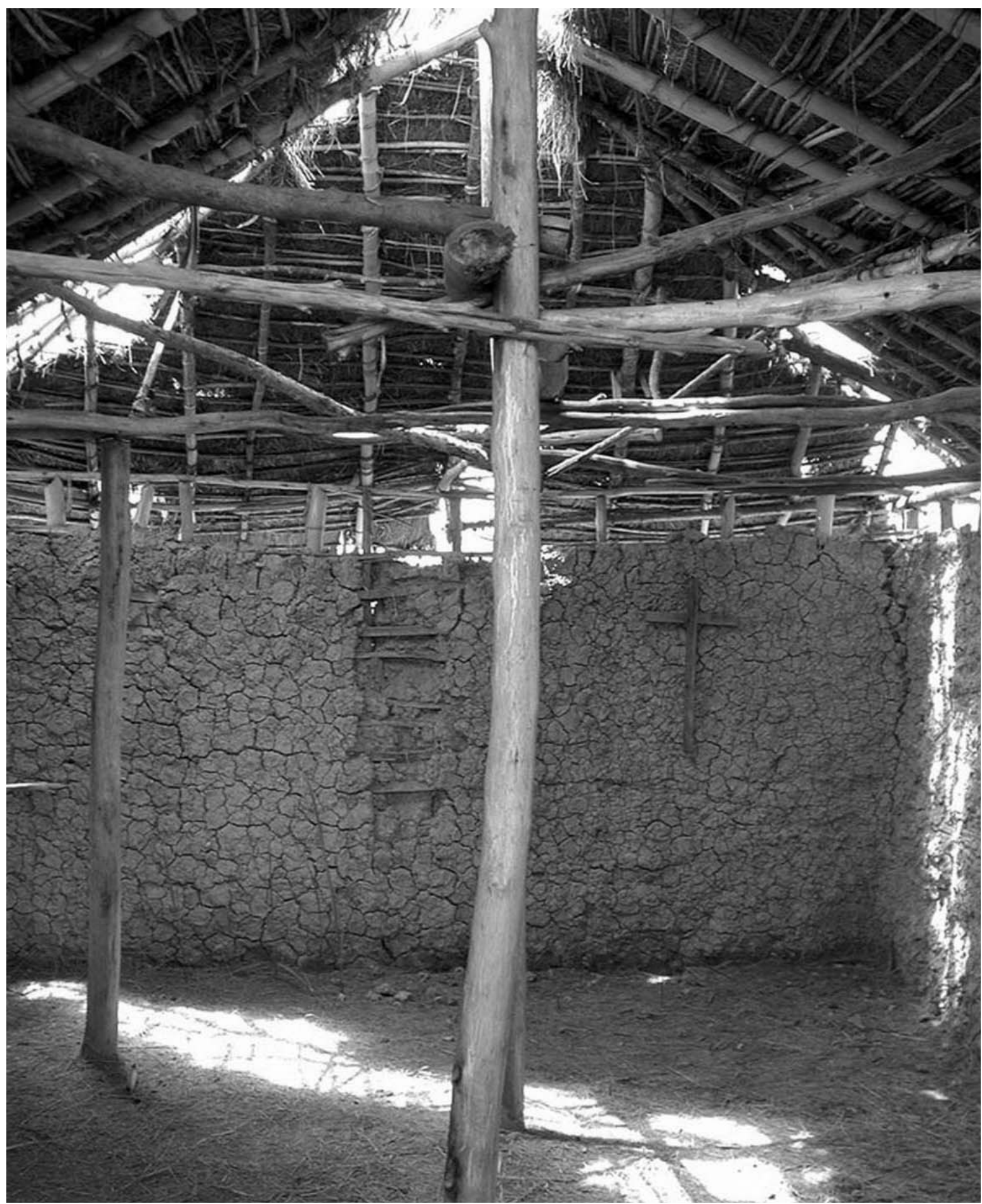

